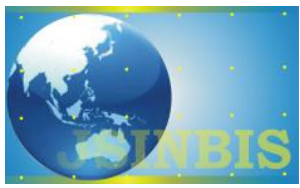

\title{
Evaluasi Kebergunaan (Usability) dan Rekomendasi Penggunaan Google Classroom untuk Blended Learning di Perguruan Tinggi
}

\author{
Agus Priyadi ${ }^{\mathrm{a}}$, Eko Sediyono ${ }^{\mathrm{b},{ }^{*}}$, Hindriyanto Dwi Purnomo ${ }^{\mathrm{c}}$ \\ Fakultas Teknologi Informasi, Universitas Kristen Satya Wacana \\ Naskah Diterima : 11 Februari 2021; Diterima Publikasi : 29 Juni 2021 \\ DOI: 10.21456/vol11iss2pp105-116
}

\begin{abstract}
The google classroom application is a virtual classroom mixed with real classes in education where the distribution of material and lecture assignments can be done by teachers and students without using paper or paperless. Interaction between teachers and students is done interactively online. The use of the google classroom application as a teaching tool has only been implemented at XYZ college, so usability testing is needed in the use of google classroom. Testing the usability level of Google Classroom is really needed to evaluate and get recommendations about using the Google Classroom application. The method used in this study is the USE (Usefullness, Satisfaction and Ease of Use) Questionnaire and Cognitive Walkthrough $(\mathrm{CW})$ used in the google classroom usability test. USE stands for Usefulness, Satisfaction, and Ease of Use. Ease of use factors can be divided into two, namely Ease of Learning and Ease of Use. The USE test involved all XYZ college students, totaling 213 respondents. Ten respondents within certain criteria were selected by purposive sampling technique to test the usefulness of using the cognitive walkthrough $(\mathrm{CW})$ method. The overall assessment of the usefulness factor with a mean value of 3.95 is included in the "Good" rating range. Overall, the satisfaction factor value of 4.01 is included in the "Good" rating range. Overall, the assessment of the Ease of use indicator with a mean of 4.22 is included in the "Good" rating range. The cognitive walkthrough (CW) method produces several recommendations that can be utilized by XYZ universities in implementing blended learning using google classroom. The usability factor with various features offered by Google Classroom is quite high because it can provide convenience in its use to support lecture activities at XYZ College.
\end{abstract}

Keywords : Usability; Google Classroom; Blended Learning.

\begin{abstract}
Abstrak
Aplikasi google classroom merupakan ruang kelas campuran antara kelas virtual dan kelas nyata dalam pendidikan dimana pembagian materi dan penugasan kuliah dapat dilakukan oleh pengajar dan mahasiswa tanpa menggunakan kertas. Interaksi antara pengajar dan siswa dilakukan secara online interaktif. Pemanfaatan aplikasi google classroom sebagai sarana mengajar baru diterapkan di perguruan tinggi XYZ, sehingga dibutuhkan pengujian usability dalam pemanfaatan google classroom. Pengujian tingkat kebergunaan google classroom sangat dibutuhkan untuk mengevaluasi dan mendapatkan rekomendasi tentang penggunaan aplikasi google classroom. Metode yang digunakan dala penelitian ini dengan USE (Usefullness, Satisfaction dan Ease of Use) Questionnnaire dan Cognitive Walkthrough (CW) digunakan dalam uji usability google classroom. USE merupakan singkatan dari Usefulness, Satisfction, dan Ease of use. Faktor Ease of use dapat dibagi menjadi dua yaitu Ease of Learning dan Ease of Use. Uji USE melibatkan seluruh mahasiswa perguruan tinggi XYZ yaitu berjumlah 213 responden. Sepuluh responden dalam kriteria tertentu dipilih dengan teknik purposive sampling untuk menguji kebergunaan menggunakan metode cognitive walktrough $(\mathrm{CW})$. Penilaian keseluruhan faktor usefulness nilai mean sebesar 3,95 masuk dalam rentang penilaian "Baik". Secara keseluruhan Nilai faktor satisfaction sebesar 4,01 masuk dalam rentang penilaian "Baik". Secara keseluruhan penilaian indikator Ease of use dengan mean sebesar 4,22 masuk dalam rentang penilaian "Baik". Metode cognitive walktrough $(\mathrm{CW})$ menghasilkan beberapa rekomendasi yang dapat dimanfaatkan oleh perguruan tinggi XYZ dalam penerapan blended learning menggunakan google classroom. Faktor usability dengan berbagai fitur yang ditawarkan oleh google classroom cukup tinggi karena bisa memberi kemudahan dalam penggunaannya untuk menunjang kegiatan perkuliahan di perguruan tinggi XYZ.
\end{abstract}

Kata Kunci : Usability; Google Classroom; Blended Learning.

*) Penulis Korespondensi : ekosed1@yahoo.com 


\section{Pendahuluan}

Teknologi informasi dan internet mendorong kebutuhan dan tuntutan perkembangan teknologi pendidikan, khususnya di masa pandemi covid-19 yang memaksa semuanya termasuk dunia pendidikan untuk melakukan pembelajaran jarak jauh atau melalui daring. Pengintegrasian sebuah inovasi didalam dunia teknologi informasi dan internet akan memunculkan blended learning, dimana intergrasi teknologi informasi dalam pembelajaran konvensional digunakan dalam mencapai tujuan pembelajaran yang efektif dan efisien. Hal ini ditandai dengan penggabungan pembelajaran konvensional dan pembelajaran daring. Perguruan tinggi menghadapi tantangan agar mampu memenuhi tuntutan konektivitas mahasiswa khususnya di era pandemi covid-19 yang belum tahu kapan berakhirnya. Institusi dituntut bisa memenuhi harapan yang berkembang dalam membangun pengalaman belajar yang lebih berkualitas dengan adanya bantuan teknologi informasi dan komunikasi internet yang mengubah banyak hal terkait perilaku masyarakat, dimana Inovasi transformatif menentukan arah pengembangan pendidikan tinggi di abad ke-21.

Dunia yang saat ini serba elektronik menuntut adanya transformasi belajar di lingkungan pendidikan tinggi. Salah satu hal yang perlu didorong adalah praktik berbasis teknologi dalam kurikulum, yang menghubungkan seluruh peserta didik tanpa terikat oleh waktu, tempat dan situasi serta dapat dilakukan dimanapun dan kapanpun berada. Dimana saat ini, pendidikan dapat diakses di mana-mana dengan menggunakan teknologi (Ventayen, Estira, Guzman, Cabaluna, \& Espinosa, 2018). Pembelajaran model ini disebut dengan istilah blended learning, yaitu biasanya digunakan untuk merujuk pada kombinasi pengajaran tatap muka dengan teknologi komputer (Hockly, 2018).

Kelebihan dan kekurangan dimiliki sistem pembelajaran online. Kelebihannya diantaranya adalah kecepatan pembelajaran tergantung masingmasing individu. Ketersediaan sarana pembelajaran bagi semua orang. Kesetaraan sosial dalam pembelajaran. Pembiayaan belajar lebih murah sehingga lebih ekonomis. Sedangkan kekurangannya adalah kurangnya tatap muka langsung antara siswa dengan pengajar. Kurangnya perhatian terhadap kondisi individu. Tidak adanya pelatihan yang dilakukan secara langsung. Kebutuhan akan sarana jaringan internet dan perangkat pendukungnya, seperti perangkat komputer dan smartphone (Filippova, 2015).

Google classroom merupakan ruang kelas virtual yang digunakan bercampuran dengan kelas nyata dalam pendidikan. Pengajar dan siswa dalam pembagian materi dan penugasan kuliah dapat dilakukan tanpa kertas (paperless) sehingga lebih menghemat sumber daya. Interaksi antara keduanya dilakukan secara online interaktif (Bondarenko, Mantulenko, \& Pikilnyak, 2019). Aktifitas interaksi dalam pembelajaran mampu dilakukan secara realtime secara efektif walaupun terpisah ruang dan jarak. Penyediaan materi belajar maupun tugas dapat dibuat dengan hyperlink ke konten multimedia. Siswa dapat mengedit dan mengomentari tugas yang dikerjakan. Sedangkan pengajar juga daat memberi pengumuman yang bisa diakses secara realtime, menetapkan deadline pengerjaan setiap tugas, serta melakukan penilaian prestasi akademik. Platform system bisa diakses tidak hanya berbasis website namun juga bisa menggunakan perangkat smartphone berbasis android yang sudah tersedia ditangan mahasiswa. Akun yang digunakan bisa login secara terus menerus, sehingga mahasiswa bisa menerima notifikasi secara otomatis tentang materi, tugas dan pengumuman dosen.

Penelitian ini terkait implementasi google classroom dalam proses belajar mengajar di perguruan tinggi yaitu perguruan tinggi XYZ yang berada di kota Semarang, Jawa Tengah. Tujuannya adalah mengevaluasi faktor usability pada aplikasi Google Classrom guna menunjang perkuliahan mahasiswa di perguruan tinggi XYZ, dimana para dosennya mulai menggunakan google classroom dalam proses belajar mengajarnya dengan mahasiswa di era pandemi covid-19. Sebelumnya uji usability google classroom belum pernah dilakukan di perguruan tinggi XYZ, sehingga hal ini sangat perlu dilakukan untuk mengidentifikasi dan menganalisis permasalahan yang dihadapi pengguna dalam hal ini mahasiswa terkait pengalamannya menggunakan google classroom agar bisa diberikan solusi serta rekomendasi ketika ada masalah untuk antisipasinya. Penelitian ini menggunakan metode Cognitive Walkthrough Usability Testing (CW) dan Use Questionnnaire (USE).

\section{Kerangka Teori}

Dalam mendukung kualitas pembelajaran secara online di perguruan tinggi sangat diperlukan adanya evaluasi dari berbagai fitur layanan pada pengguna untuk melihat aspek usability dari sebuah software (Setiawan \& Rafianto, 2020). Hubungan antara manusia dan teknologi komputer harus dibangun dalam kualitas yang baik dalam kebergunaannya (usability). Penggunaan sistem informasi dapat dibangun untuk kepentingan setiap manusia dalam memudahkan setiap pekerjaannya (Pratama \& Sediyono, 2016). Desain atau rancangan sistem informasi yang baik bersifat intuitif, dimana penggunanya dengan melihat sistem informasi berupa aplikasi komputer akan mampu melakukan sesuatu secara langsung dan benar (Purhita, 2019). Sehinga rancangan suatu aplikasi komputer mudah untuk digunakan juga mudah untuk dipelajari 
sehingga lebih berdaya guna bagi penggunanya. Aspek kebergunaan (usability) suatu aplikasi komputer penting untuk dikaji agar bisa meningkatkan daya guna dalam membantu pekerjaan manusia.

Penelitian terkait uji usability telah banyak dilakukan oleh para peneliti. Dalam sebuah sistem dan perangkat lunak aspek usability merupakan komponen penting, dimana apabila terjadi kegagalan sebuah perangkat lunak merupakan sistem yang dinilai kurang untuk mencapai tujuan dan kepuasan pengguna. (Alshehri \& Freeman, 2012). Aspek usability sangat penting untuk sistem apa pun, tetapi dalam perangkat lunak itu adalah salah satu fitur yang paling penting. Bahkan, salah satu alasan utama kegagalan perangkat lunak adalah sistem yang kurang untuk mencapai tujuan dan kepuasan pengguna.

Aelani melakukan uji usabilitas menggunakan USE Questionnare dengan parameter utamanya adalah Usefullness, Satisfaction dan Ease of Use untuk menilai kegunaan (usability) sistem perwalian online di STMIK Amik Bandung (Aelani \& Falahah, 2012). Penelitian yang melakukan pengujian usability dengan metode observasi langsung dan kuesioner untuk meningkatkan kualitas user interface aplikasi mobile (Nurhadryani et al., 2013). Adanya intervensi yang disampaikan melalui internet sangatlah penting sebagai salah satu solusi dalam menghadapi akses tatap muka (Smith et al., 2020). Sedangkan dalam sebuah penelitian yang menggunakan metode cognitive walkthrough untuk melakukan pengujian user interface pada website perpustakaan digital di Pusat dokumentasi dan Informasi Ilmiah-LIPI (Maryati et al., 2014). Menurut Raharjo et al. (2016), uji usability dengan metode cognitive walkthrough pada situs website perpustakaan Universitas Mercu Buana (UMB) Jakarta, merumuskan masalah yang dihadapi ketika pengguna ketika menggunakan situs website perpustakaan berdasarkan beberapa penjelasan pada parameter tingkat penyelesaian skenario tugas dan kesalahan. Dari langkah tersebut dapat disusun sebuah rekomendasi perbaikan-perbaikan user interface pada website Perpustakaan UMB. Melakukan monitoring dan problem solving terkait masalah usability sistus website menjadi penting untuk melihat seberapa tingkat penerimaan dan frekuensi penggunaan oleh user (Habibi et al., 2019).

Terdapat juga penelitian yang mengadopsi metode cognitive walkthrough dari Jacobsen \& John guna menguji usability user interface aplikasi Braille Smart pada siswa tunanetra di Sekolah Luar Biasa Jogjakarta (Kurnia et al., 2017). Dilakukan pengukuran tingkat efektifitas dan efisiensi dengan menggunakan tingkat keberhasilan pengguna (user's success rate) yaitu presentasi tugas yang diselesaikan dengan benar oleh pengguna.
USE Questionnaire dikembangkan oleh Arnold Lund di Ameritech, U.S WEST Advanced Technologies. USE merupakan singkatan dari Usefulness, Satisfction, dan Ease of use. Pada faktor Ease of use dapat dibagi menjadi 2 faktor, yaitu Ease of Learning dan Ease of Use. Kuesioner usability digunakan untuk mengumpulkan data yang dilaporkan sendiri dari pengguna tentang pengalaman mereka dalam menggunakan produk atau sistem tertentu. Hasil dari kuesioner ini dapat membantu para peneliti dan praktisi dalam memahami kegunaan produk dengan mengungkapkan persepsi pengguna tentang dampak dan interaksinya (Lund, 2001). Kuesioner ini dibangun dengan skala penilaian lima (5) poin atau Skala Likert. Pengguna diminta untuk menilai dengan pernyataan, mulai dari sangat tidak setuju hingga sangat setuju. Berbagai bentuk kuesioner digunakan untuk mengevaluasi sikap pengguna terhadap berbagai produk konsumen.

Cognitive Walkthrough (CW) adalah metode analisa usabilitas yang menghubungkan user interface dengan model kognitif. Dalam prosedur cognitive walkthrough, user interface pengguna digunakan untuk menguji fitur elskplorasi pada pembelajaran. Evaluator menggunakan user interface untuk menjalankan berbagai tugas yang diperlukan oleh pengguna user interface, diantaranya apakah para pengguna merasa nyaman pada penggunaan awal dan apakah pengguna memahami penggunaan user interface tanpa adanya pelatihan secara formal atau tanpa ada latar belakang pendidikan (Shekhar \& Marsden, 2018). Pengujian usability salah satu aspek yang penting dalam melakunan penilain user interface quality pengguna serta mengurangi kerugian bagi para pengguna dalam menggunakan suatu sistem (Defriani et al., 2021). Dalam membuat evaluasi berupa analisis dari user interface pengguna dengan metode cognitive walkthrough, maka diperlukan sebuah pengetahuan tentang tugas yang harus dilakukan oleh para pengguna (Bligård \& Osvalder, 2013). Cognitive walkthrough berfokus pada prinsip-prinsip dasar usability dan juga berfokus pada kegiatan kognitif pengguna, terutama pada tujuan dan pengetahuan saat melakukan tugas-tugas tertentu. Metode cognitive walkthrough dapat membantu memastikan desain user interface pada situs website dapat memenuhi kebutuhan mind mapping pengguna, mengidentifikasi bagian desain user interface yang biasanya tidak dipahami oleh dosen dan mahasiswa. Hasil evaluasi usability tersebut akan digunakan untuk merumuskan rekomendasi saran kebijakan penggunaan google classroom dalam blended learning di perguruan tinggi XYZ.

\section{Metode}

Metode pada penelitian ini terdiri dari beberapa tahapan yaitu pengujian Cognitive Walkthrough dan 
Use Questionnnaire, analisis hasil pengujian, dan rekomendasi perbaikan dalam penerapan Blended Learning menggunakan google classroom.

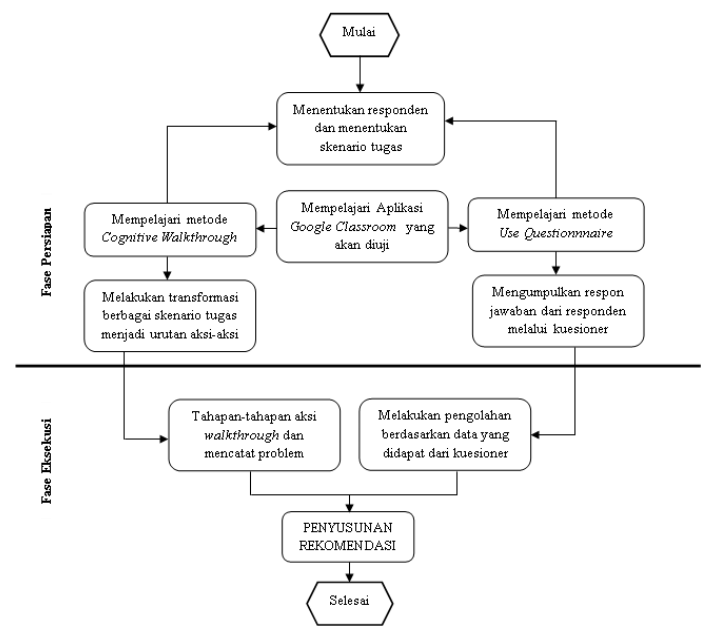

Gambar 1. Research Flowchart

Penelitian ini diawali dengan langkah mengidentifikasi masalah, dilanjutkan dengan melakukan studi pustaka yang terkait dengan uji usability dan mengkaji terhadap objek yang diamati, yaitu penggunaan google classroom sebagai media Blended Learning di perguruan tinggi XYZ.

Sedangkan pengambilan sampel menggunakan sampling jenuh atau sensus. Sampling Jenuh adalah non random sampling yang artinya semua responden selaku populasi keseluruhan memiliki kesempatan yang sama untuk dipilih menjadi sampel ((Subana \& Sudrajat, 2011). Jenis nonrandom sampling yang dipilih adalah sampling jenuh atau seluruh anggota populasi diambil sebagai sampel (Sugiyono, 2018). Dalam hal ini peneliti mencoba mengambil responden seluruh mahasiswa program studi desain grafis aktif dari angkatan 2018 sebanyak 213 orang, dengan pertimbangan merupakan mahasiswa tingkat akhir yang belum terlalu disibukkan dengan kegiatan tugas akhir.

Untuk mendapatkan hasil pengukuran uji usability pengguna google classroom, yaitu mahasiswa desain grafis perguruan tinggi XYZ maka peneliti menggunakan instrumen penelitian berupa kuesioner dengan penilaian lima poin atau skala likert, mulai sangat tidak setuju hingga sangat setuju (skala 1-5).

Pengambilan sampel dalam uji usabilitas dengan metode cognitive walkthrough (CW) menggunakan metode non random sampling yaitu purposive sampling, yang merupakan teknik sampling dimana seorang peneliti menentukan teknik sampling dengan cara menetapkan berbagai ciri khusus yang sesuai dengan tujuan penelitian yang diharapkan bisa menjawab permasalahan penelitian (Sugiyono, 2018). Sampel dalam metode Cognitive Walkthrough disebut evaluator yang terdiri dari 10 orang mahasiswa program studi desain grafis aktif dari angkatan 2018 yang didasarkan pada kemampuan dalam penggunaan aplikasi Google Classrom yang mahir dan selalu mengisi kuesioner terhadap penilaian kepada dosen di setiap semester.

\section{1. Pengukuran Usability dengan menggunakan Use Questionnaire}

Pengukuran dalam uji usability ini dengan menyusun berbagai pertanyaan yang terdapat pada kuesioner penelitian yang disebarkan ke responden terpilih. Pertanyaan-pertanyaan kuisioner yang mengacu pada tool Use questionnaire. Terdapat 19 pertanyaan penelitian yang terbagi dalam 4 faktor yaitu usefulness, satisfaction, ease of use, dan ease of learning, sesuai dengan indikator pada Use Questionnaire. Penentuan 19 item pertanyaan didasarkan pada pengembangan dari pendapat Arnold M. Lund tentang parameter USE atau Ease of Use (Aelani \& Falahah, 2012).

Pertanyaan-pertanyaan yang diberikan dalam faktor Usefulness dapat dilihat dalam tabel 1 berikut :

Tabel 1. Use Questionnaire Faktor Usefulnes

\begin{tabular}{|c|c|}
\hline KODE & Pertanyaan \\
\hline USE1 & $\begin{array}{l}\text { Apakah dengan menggunakan Google Classroom } \\
\text { memungkinkan tugas-tugas kuliah dapat diselesaikan } \\
\text { lebih cepat? }\end{array}$ \\
\hline USE2 & $\begin{array}{l}\text { Apakah dengan menggunakan Google Classroom } \\
\text { dapat meningkatkan produktivitas perkuliahan? }\end{array}$ \\
\hline USE3 & $\begin{array}{l}\text { Apakah Google Classroom dirasakan berguna dalam } \\
\text { proses perkuliahan? }\end{array}$ \\
\hline USE4 & $\begin{array}{l}\text { Apakah fitur Google Classroom memudahkan } \\
\text { penyimpan dokumen materi maupun tugas yang } \\
\text { penting? }\end{array}$ \\
\hline USE5 & $\begin{array}{l}\text { Apakah pengumuman dengan cepat (real time) } \\
\text { mudah diperoleh dengan Google Classroom? }\end{array}$ \\
\hline USE6 & $\begin{array}{l}\text { Apakah menggunakan Google Classroom lebih } \\
\text { efisien dalam pembelajaran ? }\end{array}$ \\
\hline
\end{tabular}

Pertanyaan-pertanyaan yang diberikan dalam indikator Ease of use (Kemudahan penggunaan) terlihat dalam tabel 2 berikut :

Tabel 2. Use Questionnaire Faktor Ease of use

\begin{tabular}{cl}
\hline Kode & \multicolumn{1}{c}{ Pertanyaan } \\
\hline EAS1 & $\begin{array}{l}\text { Apakah dengan menggunakan Google Classroom } \\
\text { memudahkan penyelesaian tugas-tugas kuliah ? }\end{array}$ \\
EAS2 & $\begin{array}{l}\text { Apakah pengumuman, bahan materi kuliah, maupun } \\
\text { pengumpulan tugas menjadi lebih fleksibel dengan } \\
\text { menggunakan Google Classroom ? }\end{array}$ \\
EAS3 & $\begin{array}{l}\text { Apakah mudah menggunakan Google Classroom } \\
\text { sesuai yang diinginkan? }\end{array}$ \\
EAS4 & $\begin{array}{l}\text { Apakah Google Classroom tampilannya sangat jelas } \\
\text { dan mudah untuk dipahami ? }\end{array}$ \\
EAS5 & Apakah Google Classroom mudah untuk digunakan? \\
\hline
\end{tabular}

Pertanyaan-pertanyaan yang diberikan dalam faktor Ease of Learning (kemudahan belajar) terlihat pada tabel 3 berikut : 
Tabel 3. Use Questionnaire Faktor Ease of Learning

\begin{tabular}{cl} 
Kode & \multicolumn{1}{c}{ Pertanyaan } \\
\hline LEA1 & $\begin{array}{l}\text { Apakah penggunaan Google Classroom mudah } \\
\text { dipelajari dengan cepat ? }\end{array}$ \\
LEA2 & $\begin{array}{l}\text { Apakah penggunaan Google Classroom mudah untuk } \\
\text { diingat? }\end{array}$ \\
LEA3 & $\begin{array}{l}\text { Apakah sangat mudah untuk menggunakan Google } \\
\text { Classroom secara fasih ? }\end{array}$ \\
\hline
\end{tabular}

Pertanyaan-pertanyaan yang diberikan dalam faktor Satisfction (kepuasan) terlihat dalam tabel 4 berikut :

Tabel 4. Use Questionnaire Faktor Ease of Learning

\begin{tabular}{cl} 
Kode & \multicolumn{1}{c}{ Pertanyaan } \\
\hline SAT1 & $\begin{array}{l}\text { Apakah merasa puas dengan penggunaan Google } \\
\text { Classroom untuk perkuliahan ? } \\
\text { Apakah penggunaan Google Classrom dalam } \\
\text { perkuliahan serasa menyenangkan } ?\end{array}$ \\
SAT3 & $\begin{array}{l}\text { Apakah cara kerja Google Classrom sudah seperti } \\
\text { yang diinginkan? }\end{array}$ \\
SAT4 & $\begin{array}{l}\text { Apakah Google Classrom ini luar biasa? } \\
\text { Apakah nyaman menggunakan Google Classrom } \\
\text { SAT5 }\end{array}$ \\
\hline
\end{tabular}

Terdapat tiga aspek pengukuran dalam evaluasi kebergunaan (usability) ini yaitu efisiensi, efektivitas dan kepuasan. Penilaian kuisioner dibuat dengan model skala likert dalam bentuk skor lima point. Pengukuran tingkat persetujuan pengguna terhadap pertanyaan kuisioner penelitian diolah dengan metoda kuantitatif deskriptif dalam melakukan analisis terhadap masing-masing indikator maupun keseluruhan indikator. USE questionnaire merupakan salah satu paket kuisioner non komersial yang dapat digunakan untuk penelitian uji kebergunaan (usability).

\section{1. Evaluasi Usability dengan Metoda Cognitive Walktrough}

Langkah berikutnya adalah evaluasi Usability dengan menggunakan metoda Cognitive Walktrough (CW). Diawali dengan menentukan evaluator dalam pengujian kebergunaan (usability testing). Evaluator penelitian ini adalah 10 program studi desain grafis aktif dari angkatan 2018 yang didasarkan pada kemampuan dalam penggunaan aplikasi google classroom yang mahir dan selalu mengisi kuesioner terhadap penilaian kepada dosen di setiap semester.

Prosedur metode cognitive walkthrough (CW) meliputi langkah-langkah sebagaimana berikut (Wilson, 2013):

a) Tahap perencanaan metode cognitive walkthrough $(\mathrm{CW})$ :

- Penentuan pengguna produk yang dijadikan responden.

- Merumuskan skenario tugas dan jenisnya.

- Mengembangkan aturan-aturan dasar.
- Mengurutkan tindakan untuk setiap skenario tugas.

- Memberikan gambaran user interface.

- Sekelompok evaluator disusun untuk evaluasi cognitive walkthrough.

b) Tahap pelaksanaan cognitive walkthrough :

- Pengurutan tindakan untuk skenario tugas mengacu pada perspektif pengguna produk.

- Pencatatan atau perekaman kejadian dalam pelaksanaan $C W$, meliputi: keberhasilan, kegagalan, masalah yang tidak terkait langsung $\mathrm{CW}$, asumsi pengguna, komentar tentang sekenario tugas, saran desain, dan informasi lain yang bermanfaat untuk penggunaan maupun pengembangan desain.

c) Tahap pasca cognitive walkthrough:

- Meninjau hasil CW oleh para pemangku kepentingan (stakeholders)

- Diskusi guna merumuskan solusi terbaik untuk masalah user interface yang ditemukan dalam CW.

- Menentukan solusi masalah yang akan diterapkan dalam penggunaan nantinya.

- Mengevaluasi proses CW dan guna perbaikan dalam melakukan $\mathrm{CW}$ berikutnya

Analisis terhadap tingkat keberhasilan dari seorang pengguna dinilai berdasarkan persentase skenario tugas yang diselesaikan dengan benar oleh responden, waktu penyelesaian tugas, dan berapa jumlah kesalahan yang dilakukan oleh responden. Efektivitasnya terkait dengan tingkat penyelesaian skenario tugas responden dalam mencapai tujuan penggunaan google classroom. Efisiensi terkait jumlah kesalahan yang dilakukan oleh responden dalam mencapai tujuan. Tingkat kesalahan digunakan untuk memprioritaskan masalah dan untuk mengukur tingkat kesulitan skenario tugas dibanding dengan skenario tugas lainnya. Akan dihasilkan kendala dan masalah penggunaan google classroom ketika berinteraksi dengan pengguna. Masalah yang timbul pada masing-masing skenario tugas dan analisa uji usabilitas akan menjadi dasar rekomendasi kebijakan penggunaan google clasroom dalam blended learning di perguruan tinggi XYZ.

\section{Hasil dan Pembahasan}

\subsection{Hasil Analisa Usability dengan Kuesioner}

Tingkat usability dapat diukur dengan menggunakan kuisioner dengan jenis USE Questionnaire, yang merupakan perangkat pengukuran berdasarkan pertanyaan-pertanyaan penelitian yang dibuat berdasarkan beberapa indikator. Kuesioner disebarkan pada semua responden yang terlibat dalam penelitian ini sebanyak 213 orang yang terdiri dari mahasiswa program studi desain grafis dari perguruan tinggi XYZ. 


\subsubsection{Hasil Analisa Faktor Usefulness}

Berdasarkan hasil analisis pada tabel 5 tentang faktor usefulness dari total 6 pertanyaan pada kuesioner, jawaban responden yang sering muncul adalah setuju sebanyak 510 kali $(39,91 \%)$ dan jawaban sangat setuju sebanyak 401 kali $(31,38 \%)$. Jumlah jawaban keduanya muncul 911 kali $(71,28 \%)$

Tabel 5. Hasil Penelitian Faktor Usefulness

\begin{tabular}{ccccccc}
\hline Kode & 1(STS $)$ & $2(\mathrm{TS})$ & $3(\mathrm{~N})$ & $4(\mathrm{~S})$ & $5(\mathrm{SS})$ & Jumlah \\
\hline USE1 & 4 & 12 & 42 & 83 & 72 & 213 \\
USE2 & 0 & 19 & 73 & 80 & 41 & 213 \\
USE3 & 2 & 23 & 72 & 78 & 38 & 213 \\
USE4 & 0 & 10 & 32 & 91 & 80 & 213 \\
USE5 & 0 & 1 & 15 & 95 & 102 & 213 \\
USE6 & 3 & 12 & 47 & 83 & 68 & 213 \\
\hline Jumlah & 9 & 77 & 281 & 510 & 401 & 1278 \\
\hline$\%$ & 0,70 & 6,03 & 21,99 & 39,91 & 31,38 & 100 \\
\hline
\end{tabular}

Sedangkan dalam tabel 6 variabel terlihat indikator yang memiliki skor tertinggi dan menjadi perhatian bagi pengguna adalah indikator "google classroom memudahkan saya untuk memperoleh pengumuman dengan realtime“ (USE5) dipersepsikan dengan skor tertinggi mencapai 937.

Tabel 6. Skor Faktor Usefulness

\begin{tabular}{ccccc}
\hline Kode & Jumlah & Total & $\%$ & Mean \\
\hline USE1 & 213 & 846 & 16,75 & 3,97 \\
USE2 & 213 & 782 & 15,48 & 3,67 \\
USE3 & 213 & 766 & 15,17 & 3,60 \\
USE4 & 213 & 880 & 17,42 & 4,13 \\
USE5 & 213 & 937 & 18,55 & 4,40 \\
USE6 & 213 & 840 & 16,63 & 3,94 \\
\hline Jumlah & 1278 & 5051 & 100 & 3,95 \\
\hline
\end{tabular}

Berdasarkan hasil penilaian faktor usefulness secara keseluruhan didapatkan nilai rata-rata sebesar 3,95 yang artinya masuk dalam kategori "Baik". Hal ini menunjukkan aplikasi google classroom memiliki nilai usability yang cukup tinggi menurut pengguna dan bisa dijadikan salah satu model e-learning.

\subsubsection{Hasil Analisa Faktor Ease of use}

Berdasarkan hasil analisis pada tabel 7 variabel faktor Ease of use (Kemudahan penggunaan) dari 5 pertanyaan kuisioner, maka jawaban yang sering muncul dari responden adalah setuju, yaitu sebanyak 454 kali $(42,67 \%)$ dan jawaban sangat setuju sebanyak $440(41,35 \%)$. Jumlah jawaban keduanya muncul 894 kali $(84,02 \%)$.

Hasil pada tabel 8 nampak indikator yang mempunyai skor tertinggi dan menjadi perhatian bagi pengguna adalah indicator "Dengan google classroom, memperoleh pengumuman, materi maupun pengumpulan tugas menjadi lebih fleksibel “
(EAS2) dipersepsikan dengan skor tertinggi mencapai 935 (20,84\%).

Tabel 7. Hasil Penelitian Faktor Ease of Use

\begin{tabular}{ccccccc}
\hline Kode & $1(\mathrm{STS})$ & $2(\mathrm{TS})$ & $3(\mathrm{~N})$ & $4(\mathrm{~S})$ & $5(\mathrm{SS})$ & Jumlah \\
\hline EAS1 & 2 & 15 & 38 & 84 & 74 & 213 \\
EAS2 & 0 & 0 & 19 & 92 & 102 & 213 \\
EAS3 & 0 & 13 & 34 & 88 & 78 & 213 \\
EAS4 & 0 & 5 & 25 & 95 & 88 & 213 \\
EAS5 & 0 & 3 & 16 & 95 & 98 & 212 \\
\hline Jumlah & 2 & 36 & 132 & 454 & 440 & 1064 \\
\hline$\%$ & 0,19 & 3,38 & 12,41 & 42,67 & 41,35 & 100 \\
\hline
\end{tabular}

Tabel 8. Skor Faktor Ease of use (Kemudahan Penggunaan)

\begin{tabular}{ccccc}
\hline Kode & Jumlah & Total & $\%$ & Mean \\
\hline EAS1 & 213 & 852 & 18,99 & 4,00 \\
EAS2 & 213 & 935 & 20,84 & 4,39 \\
EAS3 & 213 & 870 & 19,39 & 4,08 \\
EAS4 & 213 & 905 & 20,17 & 4,25 \\
EAS5 & 212 & 924 & 20,60 & 4,36 \\
\hline Jumlah & 1064 & 4486 & 100 & 4,22 \\
\hline
\end{tabular}

Secara keseluruhan penilaian indikator Ease of use dengan mean sebesar 4,22 masuk dalam rentang penilaian "Baik". menunjukkan bahwa aplikasi google classroom dirasakan mudah untuk digunakan. Pengguna tidak merasakan kesulitan dalam proses penggunaannya dalam pembelajaran.

\subsubsection{Hasil Analisa Faktor Ease of Learning}

Berdasarkan hasil analisis tabel 9 terlihat variabel faktor ease of learning (kemudahan belajar) dari 3 pertanyaan kuisioner, jawaban responden yang sering muncul yaitu setuju sebanyak 274 kali $(42,88 \%)$ dan jawaban sangat setuju sebanyak 254 (39,75\%). Jumlah jawaban keduanya muncul 528 kali $(82,63 \%)$

Tabel 9. Hasil Penelitian Faktor Ease of learning

\begin{tabular}{ccccccc}
\hline Kode & $1(\mathrm{STS})$ & $2(\mathrm{TS})$ & $3(\mathrm{~N})$ & $4(\mathrm{~S})$ & $5(\mathrm{SS})$ & Jumlah \\
\hline LEA1 & 0 & 5 & 20 & 96 & 92 & 213 \\
LEA2 & 1 & 16 & 38 & 84 & 74 & 213 \\
LEA3 & 0 & 3 & 28 & 94 & 88 & 213 \\
\hline Jumlah & 1 & 24 & 86 & 274 & 254 & 639 \\
\hline$\%$ & 0,16 & 3,76 & 13,46 & 42,88 & 39,75 & 100 \\
\hline
\end{tabular}

Dalam tabel 10 terdapat indikator terkait penggunaan google classroom mudah dipelajari secara cepat dengan kode pertanyaan LEA1 yang memiliki skor tertinggi, dimana para pengguna mempersepsikan dengan skor tertinggi mencapai 914 $(34,19 \%)$.

Tabel 10. Skor faktor Ease of learning

\begin{tabular}{ccccc}
\hline Kode & Jumlah & Total & $\%$ & Mean \\
\hline LEA1 & 213 & 914 & 34,19 & 4,29 \\
LEA2 & 213 & 853 & 31,91 & 4,00 \\
LEA3 & 213 & 906 & 33,89 & 4,25 \\
\hline Jumlah & 639 & 2673 & 100 & 4,18 \\
\hline$\%$ & 100 & & & \\
\hline
\end{tabular}


Hasil penilaian faktor ease of learning (kemudahan belajar) secara keseluruhan mean sebesar 4,18 masuk dalam rentang penilaian "Baik". Hal ini menunjukkan aplikasi google classroom dirasakan memiliki kemudahan dalam belajar yang baik. Itu artinya penggunaan aplikasi ini tidak ada kesulitan dalam proses belajar menggunakannya. Hal ini menunjukkan bahwa aplikasi google classroom telah dirasakan mudah untuk dipelajari. Pengguna merasa cepat dalam mempelajari cara penggunaannya.

\subsubsection{Faktor Satisfaction (Kepuasan).}

Analisis pada tabel 11 nampak variabel faktor Satisfaction (Kepuasan), dari 5 pertanyaan kuisioner, maka jawaban responden yang sering muncul adalah setuju yaitu sebanyak 414 kali $(38,87 \%)$ dan jawaban sangat setuju sebanyak $375 \quad(35,21 \%)$. Jumlah jawaban keduanya muncul 789 kali (74,08 \%) menunjukkan bahwa aplikasi google classroom telah dirasakan memuaskan, menyenangkan dan nyaman dalam penggunaannya.

Tabel 11. Hasil Penelitian Faktor Satisfaction

\begin{tabular}{ccccccc}
\hline Kode & $1(\mathrm{STS})$ & $2(\mathrm{TS})$ & $3(\mathrm{~N})$ & $4(\mathrm{~S})$ & $5(\mathrm{SS})$ & Jumlah \\
\hline SAT1 & 0 & 8 & 27 & 92 & 86 & 213 \\
SAT2 & 0 & 16 & 41 & 82 & 74 & 213 \\
SAT3 & 1 & 22 & 38 & 82 & 70 & 213 \\
SAT4 & 0 & 30 & 55 & 68 & 60 & 213 \\
SAT5 & 0 & 6 & 32 & 90 & 85 & 213 \\
\hline Jumlah & 1 & 82 & 193 & 414 & 375 & 1065 \\
\hline$\%$ & 0,09 & 7,70 & 18,12 & 38,87 & 35,21 & 100 \\
\hline
\end{tabular}

Pada tabel 12 terdapat indikator terkait kepuasan penggunaan aplikasi google classroom dengan kode pertanyaan SAT1 yang memiliki skor tertinggi, dimana para pengguna mempersepsikan kepuasan dalam menggunakan aplikasi dengan skor tertinggi mencapai 895 (20,94\%).

Tabel 12. Skor Faktor Satisfaction

\begin{tabular}{ccccc}
\hline Kode & Jumlah & Total & $\%$ & Mean \\
\hline SAT1 & 213 & 895 & 20,94 & 4,20 \\
SAT2 & 213 & 853 & 19,95 & 4,00 \\
SAT3 & 213 & 837 & 19,58 & 3,93 \\
SAT4 & 213 & 797 & 18,64 & 3,74 \\
SAT5 & 213 & 893 & 20,89 & 4,19 \\
\hline Jumlah & 1065 & 4275 & 100 & 4,01 \\
\hline
\end{tabular}

Nilai faktor kepuasan secara keseluruhan didapatkan sebesar 4,01 yang masuk dalam rentang penilaian kategori "Baik". Hal ini menunjukkan bahwa aplikasi google calssroom memiliki tingkat kepuasan pengguna yang baik atau dalam hal ini aplikasi ini cukup memuaskan dalam untuk mendukung e-learning dalam perkuliahan.
4.2. Evluasi Usabilitas Menggunakan Metode Cognitive Walktrough.

Mahasiswa pengguna google clasroom merupakan responden dalam ruang lingkup penelitian ini. Teknik purposive sampling digunakan untuk memilih sampling dalam kriteria tertentu. Karakteristik responden adalah pengguna yang telah mahir dalam mengoperasikan komputer. Pengguna juga telah mencari informasi menggunakan situs internet. Pertimbangan lain adalah pengetahuan, keterampilan dan frekuensi responden dalam menggunakan internet, web browser, website, dan search engine. Responden yang menjalankan uji usability dengan metode cognitive walkthrough adalah 10 mahasiswa pengguna google clasroom dalam perkuliahan di perguruan tinggi XYZ, hal ini sama dengan jumlah sampel responden dari penelitian dengan judul Pengujian Cognitive Walkthrough (CW) user interface perpustakaan digital (Maryati et al., 2014). Penggunaan komputer responden rata-rata lebih 4 kali per minggu. Peggunaan internet oleh responden adalah hampir setiap hari.

\subsubsection{Skenario Tugas}

Skenario tugas (ST) merupakan sekumpulan tugas yang diberikan pada responden agar dikerjakan pada saat menggunakan google classroom dalam perkuliahan. Penelitian ini menggunakan enam skenario tugas yang relevan dengan menu yang tersedia dalam google classroom.

Tabel 13. Skenario Tugas Uji Usability

\begin{tabular}{clc}
\hline ST & Tujuan & Tahapan \\
\hline ST 1 & Bergabung dengan kelas & 4 \\
ST 2 & $\begin{array}{l}\text { Melihat pengumuman kelas dan } \\
\text { mengunduh materi pembelajaran }\end{array}$ & 3 \\
ST 3 & Melihat Jadwal kegiatan perkuliahan & 4 \\
ST 4 & Membaca dan mengirimkan tugas kuliah & 8 \\
ST 5 & $\begin{array}{l}\text { Berbagi Informasi dan materi dalam } \\
\text { kelas }\end{array}$ & 4 \\
ST 6 & Melihat Nilai Tugas & 4 \\
\hline Keterangan : ST = Skenario tugas
\end{tabular}

Skenario tugas 1 (ST1) bergabung dengan kelas meliputi 4 tahapan yaitu :

a. Menyiapkan email personal guna bergabung kelas dan login,

b. masuk ke situs https://classroom.google.com,

c. meminta kode kelas pada dosen,

d. klik ikon + di sebelah kanan atas untuk gabung kelas

Skenario tugas 2 (ST2) melihat pengumuman kelas dan mengunduh materi pembelajaran meliputi 3 tahapan yaitu : 
a. Membaca pengumuman di menu forum untuk melihat pengumuman kelas

b. Klik file lampiran materi perkuliahan

c. Mengunduh file yang ada di google drive

Skenario tugas 3 (ST3) melihat Jadwal kegiatan perkuliahan meliputi 4 tahapan yaitu :

a. Klik daftar menu di kiri atas

b. Klik menu kalender

c. Klik panah kanan kiri untuk melihat kalender kegiatan selama satu minggu

d. Klik item tugas untuk melihat detail tugas yang dijadwalkan pada tanggal tertentu

Skenario tugas 4 (ST4) membaca dan mengirimkan tugas kuliah meliputi 8 tahapan yaitu :

a. Klik menu tugas kelas

b. Klik item daftar tugas yang dipilih

c. Klik menu lihat tugas

d. Klik menu tambah atau buat

e. Klik menu file untuk melampirkan tugas

f. Tarik file lampiran ke tempat lampiran atau klik menu pilih file dari perangkat

g. Klik menu Upload untuk mengunggah file tugas

h. Klik menu serahkan untuk mengirim tugas kuliah

Skenario tugas 5 (ST5) berbagi Informasi dan materi dalam kelas meliputi 4 tahapan yaitu :

a. Masuk ke menu forum

b. Klik ke kotak bagikan kelas untuk menulis pesan

c. Klik ikon lampiran untuk mengupload file materi

d. Klik tombol posting
Skenario tugas 6 (ST6) melihat Nilai Tugas Kuliah meliputi 4 tahapan yaitu :

a. Klik ikon baris menu di kiri atas

b. Klik ke menu daftar tugas

c. Klik ke menu selesai

d. Klik ke menu pilihan kelas untuk menentukan nilai kelas yang ingin dilihat

\subsubsection{Pengujian Usability Google Classroom dengan Metode Walkthrough}

Pelaksanaan pengujian berada pada laboratorium komputer XYZ yang tersambung dengan internet. Perangkat lunak Camtasia studio 8 digunakan untuk merekam aktivitas responden saat menyelesaikan skenario tugas. Dalam hal ini para responden dijelaskan tentang tujuan pengujian usability menggunakan metode walkthrough dan sekenario tugas yang akan dilakukan dan aturan pelaksanaannya. Tahapan selanjutnya para rsponden diminta kesediaannya dengan pernyataan persetujuan yang dengan bukti rekaman. Setelah dilakukan pengujian usability dengan metode walkthrough, hasil perekamannya disimpan dan ditutup dengan ditutup dengan ucapan terima kasih dan kesediaan responden akan dihubungi kembali bila diperlukan.

\subsubsection{Tingkat penyelesaian Skenario Tugas (ST) Pengguna}

Tingkat penyelesaian tugas merupakan ukuran jumlah penyelesaian setiap skenario tugas (ST) yang berhasil diselesaikan oleh setiap responden. Berdasarkan hal ini akan diketahui berapa prosentase skenario tugas yang mampu diselesaikan secara benar oleh tiap pengguna. Rekapitulasi datanya dapat dilihat dalam tabel 14 berikut ini :

Tabel 14. Rekapitulasi Penyelesaian Skenario Tugas

\begin{tabular}{ccccccccccccc}
\hline ST & R1 & R2 & R3 & R4 & R5 & R6 & R7 & R8 & R9 & R10 & Jml & Mean \\
\hline ST1 & 0 & 2 & 0 & 2 & 0 & 0 & 0 & 2 & 0 & 0 & 6 & 0,6 \\
ST2 & 0 & 0 & 0 & 0 & 0 & 0 & 0 & 0 & 0 & 0 & 0 & 0 \\
ST3 & 0 & 0 & 0 & 0 & 0 & 0 & 0 & 0 & 0 & 0 & 0 & 0 \\
ST4 & 0 & 0 & 1 & 1 & 0 & 0 & 1 & 0 & 0 & 0 & 3 & 0,3 \\
ST5 & 0 & 0 & 0 & 0 & 0 & 0 & 0 & 0 & 0 & 0 & 0 & 0 \\
ST6 & 0 & 0 & 0 & 0 & 0 & 0 & 0 & 0 & 0 & 0 & 0 & 0 \\
\hline Jml & 0 & 2 & 1 & 3 & 0 & 0 & 1 & 2 & 0 & 0 & 9 & \\
\hline Mean & 0,0 & 0,3 & 0,2 & 0,5 & 0,0 & 0,0 & 0,2 & 0,3 & 0,0 & 0,0 & & \\
\hline
\end{tabular}

Keterangan :

$\mathrm{ST}=$ Skenario tugas

$\mathrm{R}=$ Responden 
Skenario tugas yang dapat diselesaikan oleh seluruh responden dengan benar sebanyak empat skenario tugas, yaitu: melihat pengumuman kelas dan mengunduh materi pembelajaran (ST 2), melihat jadwal kegiatan perkuliahan (ST 3), berbagi informasi dan materi dalam kelas (ST 5), dan melihat nilai tugas kuliah (ST 6). Sedangkan skenario tugas yang tidak berhasil diselesaikan dengan benar sebanyak 2 sekenario tugas, yaitu: bergabung dengan kelas (ST 1) dan membaca dan mengirimkan tugas kuliah (ST 4). Sedangkan rata-rata tingkat penyelesaian skenario tugas oleh pengguna sebesar $93 \%$.

Dilihat dari sisi responden, pengguna yang mampu menyelesaikan skenario tugas dengan benar sebesar $70 \%$ responden, dan yang gagal menyelesaikan skenario tugas dengan benar sebesar $30 \%$ responden. Sedangkan responden dengan nilai terendah hanya mampu menyelesaikan skenario tugas sebesar sebesar $67 \%$.

4.2.4. Jumlah Kesalahan yang Dilakukan dalam Penyelesaian Skenario Tugas (ST) Pengguna

Kesalahan dalam penyelesaian skenario tugas yang dimaksud merupakan tindakan responden yang tidak sesuai saat uji usability berlangsung. Sedangkan jumlah kesalahan merupakan banyaknya kesalahan dalam langkah-langkah skenario tugas (ST) yang harus diselesaikan responden. Dengan mengetahui tingkat kesalahan akan membantu menentukan prioritas permasalahan dan mengukur tingkat kesulitaan diantara skenario tugas yang diberikan. Terdapat enam skenario tugas yang diberikan kepada responden agar diselesaikan secara benar. Hasil rekapitulasi terkait jumlah kesalahan penyelesaian Sekenario Tugas (ST) responden dapat digambarkan pada tabel 15 berikut ini :

Tabel 15. Rekapitulasi Jumlah Kesalahan

\begin{tabular}{ccccccccccccc}
\hline ST & R1 & R2 & R3 & R4 & R5 & R6 & R7 & R8 & R9 & R10 & Jml & Mean \\
\hline ST1 & 0 & 2 & 0 & 2 & 0 & 0 & 0 & 2 & 0 & 0 & 6 & 0,6 \\
\hline ST2 & 0 & 0 & 0 & 0 & 0 & 0 & 0 & 0 & 0 & 0 & 0 & 0 \\
\hline ST3 & 0 & 0 & 0 & 0 & 0 & 0 & 0 & 0 & 0 & 0 & 0 & 0 \\
\hline ST4 & 0 & 0 & 1 & 1 & 0 & 0 & 1 & 0 & 0 & 0 & 3 & 0,3 \\
\hline ST5 & 0 & 0 & 0 & 0 & 0 & 0 & 0 & 0 & 0 & 0 & 0 & 0 \\
\hline ST6 & 0 & 0 & 0 & 0 & 0 & 0 & 0 & 0 & 0 & 0 & 0 & 0 \\
\hline Jm1 & 0 & 2 & 1 & 3 & 0 & 0 & 1 & 2 & 0 & 0 & 9 & \\
\hline Mean & 0 & 0,3 & 0,2 & 0,5 & 0 & 0 & 0,2 & 0,3 & 0 & 0 & & \\
\hline
\end{tabular}

Keterangan :

$\mathrm{ST}=$ Skenario tugas

$\mathrm{R}=$ Responden

Skenario tugas 1 bergabung dengan kelas, kesalahan yang didapatkan adalah email pengguna yang digunakan untuk gabung kelas bukan email formal, dimana nama pengguna yang muncul dalam google classroom tidak sama dengan nama asli pengguna, sehingga tidak dikenali. Demikian pula foto profil yang digunakan merupakan gambar avatar yang tidak bisa digunakan untuk mengidentifikasi siapa penggunanya. Kesalahan yang lain adalah kode kelas yang dimasukkan tidak sesuai dengan kode kelas yang diberikan oleh dosen. Hal ini mengakibatkan gagal untuk bergabung dengan kelas.

Kesalahan yang ditemukan dalam skenario tugas 4 membaca dan mengirimkan tugas kuliah, pengguna sudah mengupload file lampiran tugas namun belum di klik tombol "diserahkan". Maka tugas tersebut akan tercatat terlambat mengirimkan tugas apabila melebihi batas waktunya karena dianggap belum "diserahkan". Pengguna sering tidak teliti dan memiliki persepsi kalau sudah di upload otomatis sudah diserahkan tugasnya, padahal masih perlu satu langkah lagi dengan menekan tombol "diserahkan" atau dalam menu bahasa Inggris tombol "turn in".

\subsection{Masalah-Masalah dan Rekomendasi Perbaikan Mekanisme Penggunaan Google Classroom}

Berdasarkan penjelasan analisa tingkat penyelesaian skenario tugas dan kesalahan, serta hasil diskusi dengan pemangku kepentingan penggunaan google classroom, ditemukan masalahmasalah yang dihadapi oleh pengguna ketika menggunakan google classroom untuk perkuliahan. Dengan ditemukannya berbagai masalah itu, maka perlu dilakukan adanya perbaikan-perbaikan dalam mekanisme penggunaannya. Disamping perlu mengoptimalkan fitur-fitur kelebihannya guna tercapai efektifitas perkuliahan dengan bantuan google classroom.

\subsubsection{Rekomendasi Skenario Tugas 1 Bergabung dengan Kelas}

Para pengguna diharapkan membuat nama email yang merepresentasikan identitas penggunanya. Terungkap adanya masalah identitas pengguna dalam gabung kelas ketika menggunakan email yang tidak formal. Identifikasi pengguna dan kecocokannya dengan data identitas formal mahasiswa tidak cocok. Perlunya adanya kebijakan dosen pengajar yang 
menggunakan classrom untuk memastikan email pengguna/ mahasiswa cocok dengan identitas formalnya. Belum terbangun kesadaran dikalangan mahasiswa bahwa diperlukan identitas yang baku dan jelas dalam dunia maya. Kredibilitas dan verivikasi identitas dalam dunia maya (internet) sekarang ini sudah menggunakan verifikasi menggunakan akun email yang terkoneksi dengan nomor SIM card handphone. Mahasiswa yang akan bergabung di kelas google classrom diwajibkan menggunakan nama akun yang sesuai identitas formal dan foto profil sesuai orangnya. Bahkan dosen bisa menolak mahasiswa yang menggunakan identitas email tidak jelas, juga bisa mengeluarkannya dari anggota kelas. Dengan identitas yang jelas dan benar maka akan memudahkan verifikasi informasi yang bisa saling dibagikan, berupa materi, tugas, pengumuman, pertanyaan dan tanggapan.

Dibutuhkan kode kelas yang khusus yang dipergunakan mahasiswa untuk gabung kelas. Kode kelas disediakan oleh google classroom, yang bisa dilakukan update sesuai kebutuhan. Hal tersebut bisa digunakan untuk membatasi anggota kelas yang memiliki hak untuk bergabung. Peserta kelas bisa diatur sesuai dengan rencana studi yang sudah diprogramkan. Hal ini juga mencegah bergabungnya peserta yang tidak berhak. Kendalanya bila mahasiswa salah menginput kodenya karena keliru maka tidak bisa gabung kelas. Harus dipastikan mahasiswa yang berhak mengetahui kode kelas bisa segera bergabung. Didalam tatapmuka perkuliahan perdana dosen bisa langsung membimbing mahasiswa melakukan input kodekelas dan memastikannya sudah bisa gabung kelas. Hasilnya memiliki kemiripan uji usabilitas dengan responden dari situs web Academic Information System (AIS) UIN Syarif Hidayatullah Jakarta, dimana hasil pengujian ini menunjukan bahwa tingkat penyelesaian skenario tugas adalah $100 \%$ (Pratama et al., 2018).

\subsubsection{Rekomendasi Skenario Tugas 2 Melihat Pengumuman Kelas dan Mengunduh Materi Pembelajaran \\ Google classroom dengan mudah mampu} menciptakan ruang virtual perkuliahan, yang bisa dengan cepat dan mudah disiapkan, dan diundang stakeholder kelas perkuliahan untuk bergabung. Akses yang murah, cepat dan gratis dapat diakses melalui website dan aplikasi android. Dimana perangkat aksesnya cukup menggunakan komputer dan HP yang sudah tersedia ditangan penggunanya, tidak memerlukan perangkat tambahan khusus.

Dosen bisa berbagi (sharing) materi dan perencanaan pembelajaran, pengumuman kegiatan kuliah, informasi temporer yang mendadak, dalam forum yang bisa secara cepat kapanpun (timeless) dimanapun (borderless), mudah diakses seluruh anggota kelas bahkan secara realtime. File lampiran bisa disertakan dalam beragam format (dokumen, gambar, video), dan langsung bisa dibuka/ dibaca maupun di download.

\subsubsection{Rekomendasi Skenario Tugas 3 Melihat Jadwal Kegiatan Perkuliahan}

Kegiatan kelas ditata secara otomatis dalam timeline kalender mingguan. Sehingga anggota kelas mudah untuk melihat jadwal kegiatan dalam kalender. Penelusuran secara cepat dalam jadwal kalender memudahkan pengguna untuk mengelola kegiatan kuliah. Item agenda kegiatan dalam kalender terkoneksi dengan halaman detail kegiatannya.

\subsubsection{Rekomendasi Skenario Tugas 4 Membaca dan Mengirimkan Tugas Kuliah}

Pengajar dapat membuat kelas virtual dalam google classroom, juga bisa memberikan penugasan, mengkomunikasikan dan melakuan pengelolaannya di kelas virtual tersebut. Instruksi tugas mudah dikomunikasikan dan bisa cepat menerima feedback. Pengumuman tugas dan diskusi kelas bisa diselenggarakan secara live.

Pengelolaan informasi perkuliahan bisa dilakukan lebih baik, siswa dapat mengakses informasi perkuliahan di halaman tugas, di forum kelas maupun di kalender kelas. Semua materi informasinya serta materi tugas yang dikirimkan otomatis dapat tersimpan dalam berkas google drive. Dokumen pengajar maupun mahasiswa dikelola secara otomatis. Pengelolaan data secara digital sangat menghemat ruang simpan, waktu maupun material penyimpanan berupa kertas.

Perlu kecermatan dalam teknis upload dan pengiriman tugas pada pengajar. Terdapat mekanisme terpisah antara upload dokumen dan status penyerahannya lewat tombol "turn in / tandai sudah selesai". Karenanya dosen perlu melihat folder tugas mahasiswa yang statusnya sudah diupload tapi belum diserahkan agar di tekan tombol "turn in/ tandai sudah selesai". Hal tersebut dilakukan agar tidak dianggap terlambat dalam menyerahkannya walau sudah di upload.

\subsubsection{Rekomendasi Skenario Tugas 5 Berbagi Informasi dan Materi dalam Kelas}

Siswa dapat berbagi materi, berkomunikasi dalam forum kelas. Ruang chat yang bisa disertai file lampiran dengan beragam format. Materi informasi yang bisa dibuka secara langsung, tanpa software pembuka tambahan, memudahkan akses informasinya.

\subsubsection{Rekomendasi Skenario Tugas 6 Melihat Nilai Tugas Kuliah}

Pengajar juga dapat melihat dengan cepat siapa saja yang sudah dan belum menyelesaikan tugas. File tugas dalam beragam format yang langsung bisa 
dibaca, mempercepat proses penilaian dosen agar langsung memberikan nilai dan masukan secara realtime. Mahasiswa langsung bisa melihat hasil penilaian dosen ketika nilai diberikan. Hal ini sesuai dengan hasil penelitian pengujian e-library menggunakan metode cognitive walkthrough, dimana semua parameter yang dinilai mengalami keberhasilan dalam penyelesaian tugas, dan efektivitas pelaksanaan tugas (Maryati et al., 2014).

\section{Kesimpulan}

Faktor kegunaan (usability) google classroom cukup tinggi karena bisa memberi kemudahan dalam penggunaannya untuk menunjang kegiatan perkuliahan di perguruan tinggi. Dengan berbagai fitur yang ditawarkan oleh google classroom membuat penggunanya mudah dalam pengoperasiannya atau effortless. Implementasi penggunaan aplikasi google classroom mampu memberikan daya dukung usability pada sistem perkuliahan online atau blended learning. Perubahan perilaku belajar berbasis online, dengan kecepatan dan kemudahan akses, kelengkapan materi dengan beragam media, kemudahan penggunaannya mendorong peningkatan motivasi belajar. Sistem aplikasi pembelaaran yang digunakan cukup efisien dengan menggunakan berbagai perangkat teknologi yang sudah tersedia dilingkungan infrastruktur penggunanya (komputer dan smartphone). Sistem pembelajaran berbasis teknologi yang ditawarkan google classroom memberi banyak kemudahan dalam proses persiapan, implementasi dan evaluasi pembelajaran. Penghematan sumberdaya ruang simpan, material paperless, dan efisiensi pembelajaran di perguruan tinggi.

\section{Daftar Pustaka}

Aelani, K. and Falahah, 2012. Pengukuran usability sistem menggunakan use questionnaire. Seminar Nasional Aplikasi Teknologi Informasi, 15-16.

Alshehri, F and Freeman, M., 2012. Methods of usability evaluations of mobile devices. ACIS 2012: Proceedings of the 23rd Australasian Conference on Information Systems.

Bligård, L.O. and Osvalder, A.L., 2013. Enhanced cognitive walkthrough: Development of the cognitive walkthrough method to better predict, identify, and present usability problems. Advances in Human-Computer Interaction, 2013. https://doi.org/10.1155/2013/931698

Bondarenko, O.V., Mantulenko, S.V and Pikilnyak, A.V., 2019. Google classroom as a tool of support of blended learning for geography students. arXiv.

Defriani, M., Resmi, M.G., Jaelani, I., 2021. Uji Usability dengan metode Cognitive Walkthrough dan System Usability Scale (SUS) pada situs web
STT Wastukancana. Journal of Information Technology and Computer Science (INTECOMS), 4(1): 30-39.

Filippova, T., 2015. Priority fields of e-learning development in Russia. Procedia - Social and Behavioral Sciences, 206: 348-353. https://doi.org/10.1016/j.sbspro.2015.10.063

Habibi, S., Akbari, L.S., Miandoab, A.T., and Soltani, T.S., 2019. Usability of central library websites of Iranian Universities of Medical Sciences: An Evaluation. DESIDOC Journal of Library and Information Technology, 39(4): 162168. https://doi.org/10.14429/djlit.39.4.14462

Hockly, N., 2018. Application of the Blended Learning Model During the Teaching of the "Foreign Language for Professional Use" Course. ELT, 72(1):97-101.

Kurnia, R.S., Utami, E., Fatta, H., Al Road, J.R and Catur, C., 2017. Pengujian Usability Antarmuka Aplikasi Braille Smart. 2(1), 21-28.

Lund, A.M., 2001. Measuring usability with the USE questionnaire. Usability Interface, 8(2):3-6.

Maryati, I., Ardiansyah, F. and Kusuma, W., 2014. Pengujian Cognitive Walkthrough Antarmuka Perpustakaan Digital (E-Library) Pusat Dokumentasi dan Informasi Ilmiah - LIPI (PDIILIPI). Jurnal Dokumentasi dan Informasi, 35(1):25-40.

Nurhadryani, Y., Sianturi, S.K., Hermadi, I. dan Khotimah, H., 2013. Pengujian usability untuk meningkatkan antarmuka aplikasi mobile. Jurnal Ilmu Komputer dan Agri-Informatika, 2(2):83-93. https://doi.org/10.29244/jika.2.2 .8.

Pratama, A.V., Qomariah, T.J., Mahaerani, H., Setiadi, F and Zultari, M.D., 2018. Uji usability situs web academic information system (AIS) Uin Syarif Hidayatullah Jakarta dengan metode Cognitive Walkthrough. UIN Syarif Hidayatullah Jakarta, 0-6.

Pratama, F.A., Sediyono, E., 2016. Analisis Perbandingan sistem informasi perjalanan dinas berdasarkan elements Human Computer Interaction (HCI) (Studi Kasus : Dinas Kesehatan Provinsi Kalimantan Barat). Jurnal Teknologi Informasi dan Ilmu Komputer, 3(2): 110. https://doi.org/10.25126/jtiik.201632178

Purhita, E. J., 2019. Affordance dalam desain Intuitif dan Human Computer Interaction (HCI). Jurnal Teknologi Informasi dan Komunikasi, 10(1): 714.

Raharjo, P., Kusuma, W.A., \& Sukoco, H., 2016. Uji usability dengan metode Cognitive Walkthrough pada situs web perpustakaan Universitas Mercu Buana Jakarta. Jurnal Pustakawan Indonesia, 15(1-2).

Setiawan, D dan Rafianto, N., 2020. Pengukuran usability pada learning management system perguruan tinggi menggunakan pedoman system usability scale. Teknologi: Jurnal Ilmiah Sistem 
$\begin{array}{lcr}\text { Informasi, } & 10(1), & 23-31 \\ \text { https://doi.org/10.26594/teknologi.v10i1.2010 }\end{array}$ Shekhar, A. and Marsden, N., 2018. Cognitive walkthrough of a learning management system with gendered personas. ACM International Conference Proceeding Series, 191-198. https://doi.org/10.1145/3196839.3196869

Smith, A., Ben, Bamgboje, A., Butow, P., Klein, B., Turner, J., Sharpe, L., Girgis, A., 2020. Development and usability evaluation of an online self-management intervention for fear of cancer recurrence (iConquerFear). PsychoOncology, 29(1), 98-106. https://doi.org/10.1002/pon.5218

Subana dan Sudrajat, 2011. Dasar-dasar Penelitian Ilmiah. Surakarta. Pustaka Setia.
Sugiyono, 2018. Metode Penelitian Kuantitatif,Kualitatif dan R\&D. In ke-26 (p. 334). Retrieved from www.cvalfabeta.com

Ventayen, R.J.M., Estira, K.L.A., Guzman, M.J.De., Cabaluna, C.M. and Espinosa, N.N., 2018. Usability evaluation of google classroom: basis for the adaptation of gsuite e-learning platform software management view project data analysis view project. Asia Pacific Journal of Education, Arts and Sciences, 5(1), 47-51.

Wilson, C., 2013. User Interface Inspection Methods: A User-Centered Design Method. In User Interface Inspection Methods: A User-Centered Design Method. https://doi.org/10.1016/C2012-006519-2 